\section{Original Research}

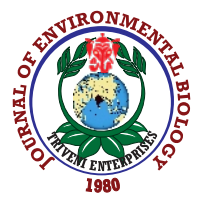

DOI : http://doi.org/10.22438/jeb/41/4/MRN-1305

Journal Home page : www.jeb.co.in « E-mail : editor@jeb.co.in Journal of Environmental Biology CODEN: JEBIDP
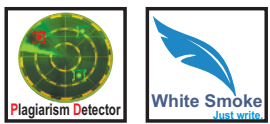

\title{
Fatty acid profiles of Antarctic cyanobacteria Leptolyngbya
}

\author{
Z.A. Zainal Abidin ${ }^{1}$, Z. Zainuddin ${ }^{2 *}$, S.F.Q. Wan Mastrai ${ }^{1}$, F.M. Mohd Sidik Merican ${ }^{3}$ and P. Convey ${ }^{4}$ \\ 'Department of Biotechnology, Kulliyyah of Science, International Islamic University Malaysia, Kuantan-25200 Pahang, Malaysia \\ ${ }^{2}$ Department of Plant Science, Kulliyyah of Science, International Islamic University Malaysia, Kuantan-25200 Pahang, Malaysia \\ ${ }^{3}$ School of Biological Sciences, Universiti Sains Malaysia, 11800, Penang, Malaysia \\ ${ }^{4}$ British Antarctic Survey, NERC, Cambridge, CB3 OET, United Kingdom
}

*Corresponding Author Email : zzarina@iium.edu.my

\section{Abstract}

Aim: Antarctic cyanobacteria may represent a potential resource of new and unique compounds with interesting capabilities. Profiling of fatty acids in Antarctic cyanobacteria can provide an overview of potential fatty acids present in them, that can be utilised in future applications.

Methodology: In total, 4 cyanobacteria previously isolated from Antarctic polar ice was used in this study. Molecular identification using 16S rRNA gene was used to ascertain their identities as Leptolyngbya spp. and their fatty acid profiles were determined using GCMS.

Results: Morphologically, these cyanobacteria were found similar to Leptolyngbya sp. Analysis of $16 S$ rRNA gene sequences amplified further confirmed their identity and were designated as Leptolyngbya sp. A, B, D and $\mathrm{E}$. Following fatty acid analysis using GCMS, it was determined that unsaturated fatty acids predominated the fatty acid profiles for Leptolyngbya sp. $A, B$ and $D$, while saturated fatty acid was found dominant in Leptolyngbya sp. E. Leptolyngbya sp. D contained almost $100 \%$ of linoleic acid, whilst Leptolyngbya sp. A and Leptolyngbya sp. B contained 59.35\% and $83.33 \%$ of linoleic acid, respectively. Besides linoleic acid, palmitoleic acid $(18.45 \%)$, oleic acid (19.45\%) and lauric acid $(2.74 \%)$ were also present in Leptolyngbya sp. A. As for Leptolyngbya sp. B, other than linoleic acid, only oleic acid $(16.67 \%)$ was detected.

Interpretation: Findings from this study demonstrate that the Antarctic Leptolyngbya spp. A, B and D identified in this study possess high content of unsaturated fatty acids, while only saturated fatty acid was present in Leptolyngbya sp. E. Fatty acid profiles revealed the potential of these Antarctic Leptolyngbya species to be further exploited for other applications.

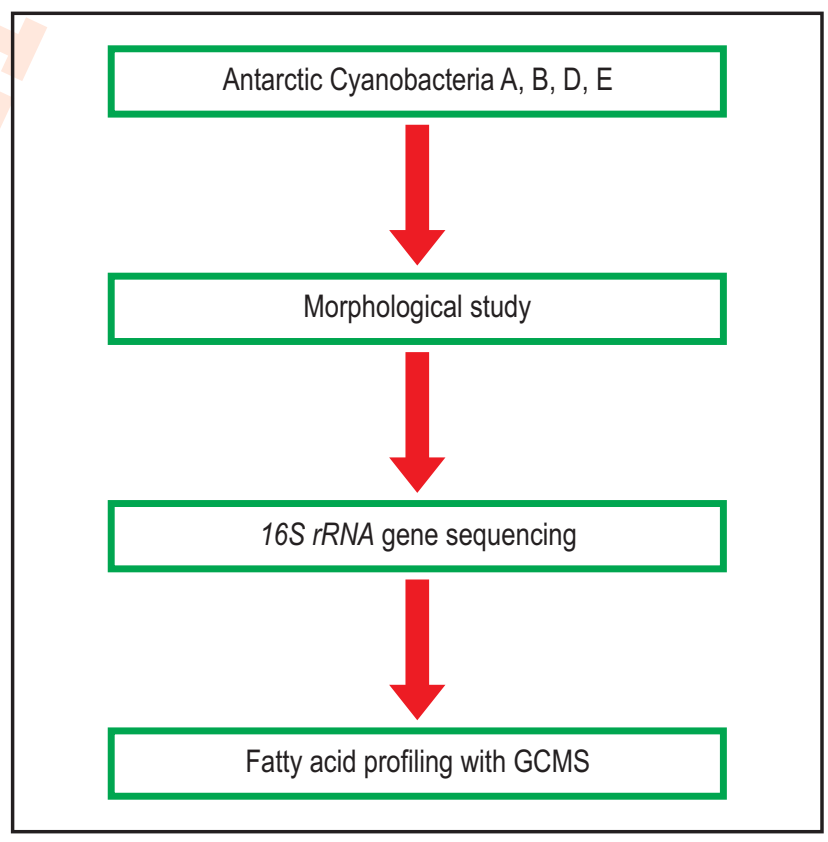

Keyword: 16S rRNA, Antarctic region, Cyanobacteria, Fatty acid profiles, Leptolyngbya

How to cite : Zainal Abidin, Z.A., Z. Zainuddin, S.F.Q. Wan Mastrai, F.M. Mohd Sidik Merican and P. Convey: Fatty acid profiles of Antarctic cyanobacteria Leptolyngbya. J. Environ. Biol., 41, 687-694 (2020). 


\section{Introduction}

Cyanobacteria are prokaryotes that are capable of photosynthesis and mostly exist in illuminated environments. These microorganisms contribute oxygen to the earth due to their photosynthetic property and presence of chlorophyll a (Sharma et al., 2013; Bela and Malliga, 2015). Cyanobacteria are predominantly known as blue-green algae due to the presence pigments phycobilin and phycocyanin (Schopf, 2012). Cyanobacteria exist in a wide-ranging shapes and sizes. The basic morphological shapes are spherical, rod or spiral, and they can also grow in colonies or filaments (Singh and Montgomery, 2011). Unicellular cyanobacteria exists as single cells, suspended or benthic, or aggregates, while filamentous type may be thin or thick, single trichome or bundles either with or without a sheath (Abed et al., 2009). Due to their vast availability throughout cold habitats, cyanobacteria are model microorganisms for the reconstruction of microbial life on the primitive earth.

Cyanobacterial populations are expanding and dominating many environments, particularly freshwater lakes, basins, rivers, irrigation channels, brackish, sea waters and salty lakes (Manganelli et al., 2012). In extreme cold temperature of Antarctic, Arctic and alpine environment, cyanobacteria are of basic ecological importance as primary producers and ecosystem engineers (Chrismas et al., 2018). Cyanobacterial mats are common in Antarctic lakes, pond and on moist soils. The extreme condition in Antarctic makes it a non-conducive habitat for living things and requires remarkable adaptive mechanism to survive in harsh environment. Such includes the non-stop cold temperature, accompanied by freeze-thaw cycles, irradiation with extreme fluctuation as well as differences in supply of nutrients and salinity. However, cyanobacteria found in ice and cold desert habitats are equipped with mechanisms to survive the harshness of surroundings. For example, some dwell in rocks where humidity is high, and thermal differences are not that significant. They also form dark mats on or within ice where temperature is high enough to be able to obtain water as well as absorbing sunlight. Interestingly, most cyanobacteria in cryosphere are actually psychrotrophic (cold tolerant), instead of psychrophiles (Oliver et al., 2012). This is reinforced by Üveges and co-workers (2012) that polar cyanobacteria has originated from temperate regions of warmer temperature due to the fact that Antarctic cyanobacteria cannot grow at temperatures lower than $5^{\circ} \mathrm{C}$ but can grow between $5^{\circ}-30^{\circ} \mathrm{C}$. Although cyanobacteria do not have high metabolism rate and grow slowly, they have broad tolerance to polar condition.

They are able to survive dormancy and are resistant to natural loss which make cryosphere conducive habitat for them. Even with optimum conditions, they take longer time to grow as compared to psycrophilic algae (Vincent, 2007). Some of the species found in the polar region include Anabaena sp., Leptolyngbya sp., Nostoc sp., Synechococcus sp., and
Oscillatoria sp. (Oliver et al., 2012). Leptolyngbya sp. are filamentous cyanobacterium clustered together with the genus Plectonema, Lyngbya and Phormidium (Rippka et al., 1979). This cyanobacterium is widely distributed in different habitats such as marine, deserts and freshwater environments (Wilmotte and Herdman, 2001). Morphological characteristics of genus comprises of thin trichomes and sometimes sheaths (Castenholz, 2001). Due to the small size and simple morphology, it complicates the taxonomic classification of Leptolyngbya sp. Some species of Leptolyngbya from Antarctic have been identified as $L$. vincentii sp. nov, L. nigrescens sp. nov, $L$. fritschiana sp. nov and L. borchgrevinkiisp. nov. (Komárek, 2007).

Cyanobacteria have substantial amount of fatty acids which consequently aid in their survival in cold habitats. The adaptive mechanism is influenced by the composition of membrane fatty acids whereby it controls the fluidity and metabolic functions (Králová, 2017). It is proved that low chain lengths of polyunsaturated fatty acids are integrated in the cell membranes in order to retain the fluidity of membrane at low temperatures (Zakhia et al., 2008). A comparison between Antarctic cyanobacteria and the ones from New Zealand have shown similarities in the abundance of palmitic, stearic and oleic acid, where the latter is unsaturated (Martineau et al., 2013). Fatty acid composition is important as it elucidates the potential sources of commercially intriguing fatty acids which could drive big industries such as food and biofuel. One of the potential applications of palmitic acid is lowering fatty acid oxidation and increased daily energy expenditure, helps in reducing weight and total lipid content as well as circulating the insulin level (Kien et al., 2018). It has been demonstrated that palmitic acid induced degeneration of myofibrils and modulate apoptosis in adult rat cardiomyocytes where it could open the pathway for further research to be implemented on humans (Dyntar et al., 2001). Oleic acid is omega-9 unsaturated fatty acid, commonly found in various types of plants including olive oil and almond oil. It helps in reducing high blood pressure (Terés et al., 2008). It was reported that the fatty acid methyl ester (FAME) content of Leptolyngbya BL0902 obtained from microalgae culture plant is $18.9 \%$ which comprises mainly of palmitic acid (Taton et al., 2012). In Leptolyngbya sp. KIOST-1 (isolated from an open pond), constitutes $21.4 \%$ of stearic acid (Kim et al., 2015). To date, fatty acids profile of polar Leptolyngbya $\mathrm{sp}$. is yet to be explored.

Other than playing a prominent role in survival, fatty acids also contribute in identification of cyanobacteria from the patterns formed by fatty acid profiles. Further analysis via molecular identification helps in documentation of species, based on the conserved region in the fragment of 16S rRNA gene from the records in NCBI GenBank. Hence, this study was conducted with the aim to identify four samples of cyanobacteria collected from Antarctic, and to profile their fatty acid composition. 


\section{Materials and Methods}

Cyanobacteria: Leptolyngbya sp. samples were isolated from polar ice in Antarctic by the members of Universiti Sains Malaysia (USM) and British Antarctic Survey (BAS). The samples were labelled as Leptolyngbya sp. A, B, D and E. These strains were maintained in BG-11 media agar. Leptolyngbya sp. A, B, D and $E$ were identified by using a light microscope at 40-100x magnification. The morphological features such as size, shape of colonies and filaments were noted as proposed by Komárek (2007).

Molecular identification: Genomic DNA extraction was performed on Leptolyngbya sp. A, B, D and E using the conventional phenol-chloroform method. Next, PCR amplification of $16 S$ rRNA gene was conducted on the extracted genomic DNA using two universal primers: 5'-AGAGTTTGATCCTGGC TCAG3' (forward) and 5'-GGTTACCTTGTTACGACTT-3' (reverse). The reaction mixture was prepared in a total volume of $50 \mu \mathrm{l}$ containing $5 \mu \mathrm{l}$ of extracted DNA, $1 \mu \mathrm{l}$ of each primer, $25 \mu \mathrm{l}$ of Mastermix containing Taq polymerase, dNTPS, BSA and reaction buffer. PCR temperature profile was as follow: $94^{\circ} \mathrm{C}$ for $5 \mathrm{~min}, 30$ cycles of $95^{\circ} \mathrm{C}$ for $30 \mathrm{sec}, 60^{\circ} \mathrm{C}$ for $30 \mathrm{sec}, 72^{\circ} \mathrm{C}$ for $2 \mathrm{~min} 30 \mathrm{sec}$ and finally an extension step at $72^{\circ} \mathrm{C}$ for $10 \mathrm{~min}$. Amplification products were analyzed by electrophoresis in $1 \%(\mathrm{w} / \mathrm{v})$ agarose gels stained with $1 \mu \mathrm{l}$ Midori Green staining solution. After visualization with Alpha Imager, single bands of 1500 bp were cut and inserted into $1.5 \mathrm{ml}$ microcentrifuge tubes. The samples were sent to Apical Scientific Sdn. Bhd. for purification and sequencing. The resultant 16S rRNA gene sequences were manually verified and edited using BioEdit Sequence Alignment Editor. Partial nucleotide sequences were compared with GenBank database via BLASTn search tool.
Fatty acid analysis: Fatty acid profile of Leptolyngbya A, B, D and $E$ were estimated by the method described by Sasser (1990). The isolates were grown in BG-11 agar for 14 days at $23^{\circ} \mathrm{C}$. Approximately, $40 \mathrm{mg}$ of bacterial cells were placed in $15 \mathrm{ml}$ centrifuge tube. To this tube, $1 \mathrm{ml}$ of Reagent 1 (45 g sodium hydroxide, $150 \mathrm{ml}$ methanol, $150 \mathrm{ml}$ distilled water) was added, and the tubes were vortexed and heated in a boiling water bath for $5 \mathrm{~min}$, and vigorously vortexed for $5-10 \mathrm{sec}$ and returned to water bath to complete the $30 \mathrm{~min}$ heating. Then, $2 \mathrm{ml}$ of Reagent 2 ( 325 $\mathrm{ml} 6.0 \mathrm{~N}$ hydrochloric acid, $275 \mathrm{ml}$ methyl alcohol) was added. After vortexing, the tubes were heated for $10 \pm 1 \mathrm{~min}$ at $80^{\circ} \pm 1^{\circ} \mathrm{C}$. Next, $1.25 \mathrm{ml}$ of Reagent $3(200 \mathrm{ml}$ hexane, $200 \mathrm{ml}$ methyl tertbutyl ether) were added to cooled tube followed by recapping and gentle tumbling on a clinical rotator for about $10 \mathrm{~min}$. The aqueous (lower) phase were pipetted out and discarded. About $3 \mathrm{ml}$ of Reagent 4 (10.8 g sodium hydroxide dissolved in $900 \mathrm{ml}$ distilled water) was added to organic phase remaining in the tube. The tubes were recapped, and then tumbled for $5 \mathrm{~min}$. About $2 / 3$ of organic phase was pipetted into a vial and sent for analysis. Determination of fatty acid profiles of cyanobacteria was carried out with gas chromatography mass spectrometer (GC-MS) with run time of $40 \mathrm{~min}$, temperature of $30^{\circ} \mathrm{C}$ per minute and increased in $5^{\circ} \mathrm{C}$ per minute until it reached $200^{\circ} \mathrm{C}$ with holding time of $5 \mathrm{~min}$.

\section{Results and Discussion}

Leptolyngbya spp. A, B and E showed similar morphology of dark green thin filamentous morphology (Fig. 1) whereas Leptolyngbya sp. D was particularly different due to the growth of colonies that were contoured in shape and had more compact morphological feature. Further inspection under microscope revealed all samples were found to be filamentous (Fig. 1). Leptolyngbya spp. A, B and E all were similar in size while
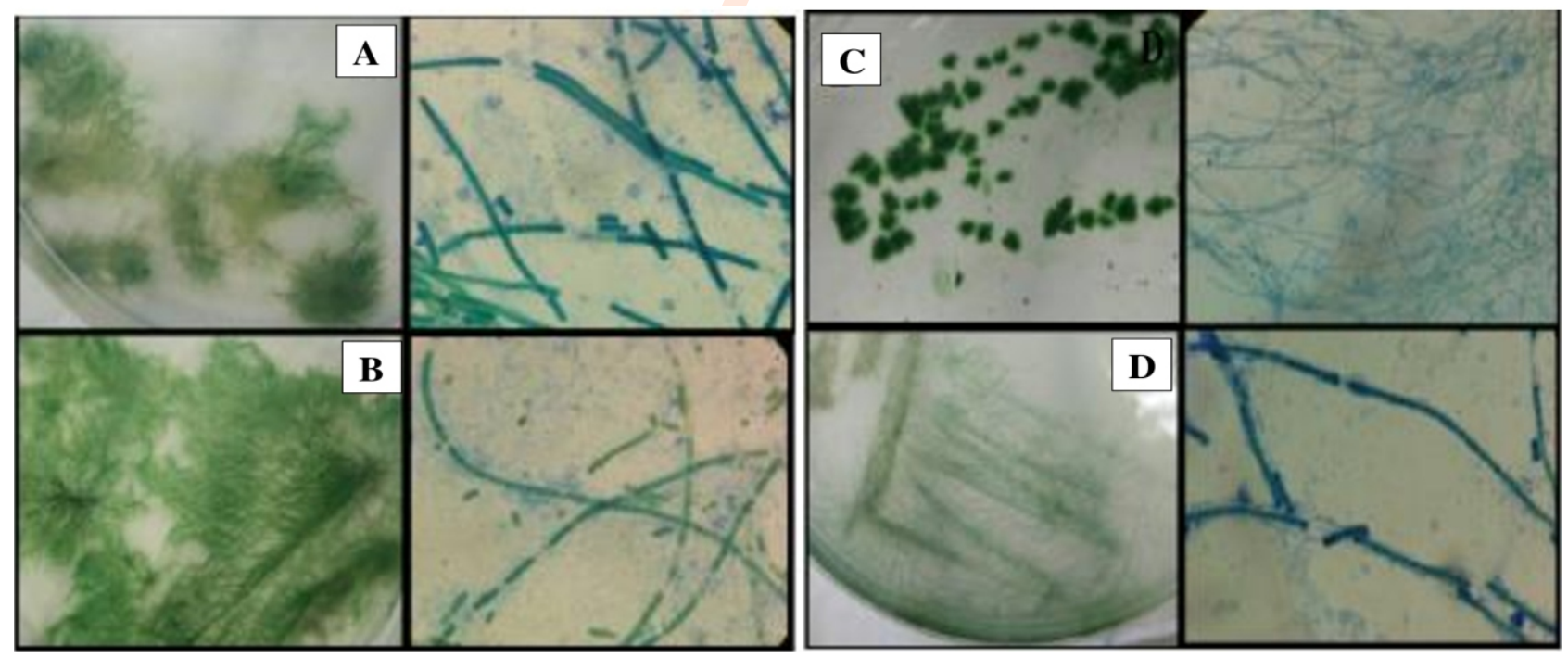

Fig. 1: Morphological images of colonies and filaments of (A) Leptolyngbya sp. A; (B) Leptolyngbya sp. B; (C) Leptolyngbya sp. D and (D) Leptolyngbya sp. $\mathrm{E}(1000 \mathrm{x})$. 
Table 1: Comparison of partial 16S rRNA gene sequences with NCBI GenBank Database

\begin{tabular}{lll}
\hline Isolate & Closest match & Similarity $(\%)$ \\
\hline A & Leptolyngbya valderiana BDU 30711 & 97 \\
B & Leptolyngbya valderiana BDU 30711 & 98 \\
D & Leptolyngbya sp. O-77 & 98 \\
E & Leptolyngbya valderiana BDU 140081 & 98 \\
\hline
\end{tabular}

Table 2 : Composition of different type of fatty acids of Leptolyngbya spp. A, B, D and E detected by GC-MS

\begin{tabular}{|c|c|c|c|c|c|c|}
\hline \multirow[b]{3}{*}{ Common name } & \multicolumn{2}{|l|}{ Fatty acid } & \multicolumn{4}{|c|}{ Fatty Acid (\%) } \\
\hline & \multirow[b]{2}{*}{ Molecular formula } & \multirow[b]{2}{*}{ Systemic name } & \multicolumn{3}{|c|}{ Leptolyngbya } & \multirow[b]{2}{*}{$E$} \\
\hline & & & A & B & D & \\
\hline $\begin{array}{l}\text { Lauric acid } \\
\text { Stearic acid } \\
\text { Heptatriacontanoic acid } \\
\text { Total FA(\%) }\end{array}$ & $\begin{array}{l}\mathrm{C}_{12} \mathrm{H}_{24} \mathrm{O}_{2} \\
\mathrm{C}_{18} \mathrm{H}_{34} \mathrm{O}_{3} \\
\mathrm{C}_{37} \mathrm{H}_{72} \mathrm{O}_{5}\end{array}$ & $\begin{array}{l}\text { Saturated } \\
\text { Dodecanoic }(12: 0) \\
\text { Octadecanoic }(18: 0) \\
\text { Heptatriacontanoic }(37: 0)\end{array}$ & $\begin{array}{l}2.74 \\
\text { nd } \\
\text { nd } \\
2.74\end{array}$ & $\begin{array}{l}\text { nd } \\
\text { nd } \\
\text { nd }\end{array}$ & $\begin{array}{l}\text { nd } \\
\text { nd } \\
\text { nd }\end{array}$ & $\begin{array}{l}\text { nd } \\
83.0 \\
17.0 \\
100\end{array}$ \\
\hline $\begin{array}{l}\text { Palmitoleic acid } \\
\text { Oleic acid }\end{array}$ & $\begin{array}{l}\mathrm{C}_{16} \mathrm{H}_{30} \mathrm{O}_{2} \\
\mathrm{C}_{18} \mathrm{H}_{34} \mathrm{O}_{2}\end{array}$ & $\begin{array}{l}\text { Monounsaturated } \\
\text { 9-Hexadecenoic (9-16:1) } \\
\text { 9-Octadecenoic (9-18:1) }\end{array}$ & $\begin{array}{l}18.45 \\
19.45\end{array}$ & $\begin{array}{l}\text { nd } \\
16.67\end{array}$ & $\begin{array}{l}\text { nd } \\
\text { nd }\end{array}$ & $\begin{array}{l}\text { nd } \\
\text { nd }\end{array}$ \\
\hline $\begin{array}{l}\text { Linoleic acid } \\
\text { Total FA(\%) }\end{array}$ & $\mathrm{C}_{18} \mathrm{H}_{32} \mathrm{O}_{2}$ & $\begin{array}{l}\text { Polyunsaturated } \\
\text { 9,12-Octadecedienoic }(9,12-18: 2)\end{array}$ & $\begin{array}{l}59.35 \\
97.26\end{array}$ & $\begin{array}{l}83.33 \\
100\end{array}$ & $\begin{array}{l}100 \\
100\end{array}$ & $\begin{array}{l}\text { nd } \\
\text { nd }\end{array}$ \\
\hline
\end{tabular}

*nd: not detected

Leptolyngbya sp. D was comparatively smaller than the rest. Leptolyngbya sp. A had thin and straight filaments with distinct trichomes. The sheaths were thin and the content of cells was dark green. The apical cells were round in shape whereas. Leptolyngbya sp. B had long, thin and straight filaments. Trichomes were not as distinct as sample $A$ and the cellular content which was also green, appeared to be a shade lighter than sample A. The sheaths were also thin and the end of cells were round. Leptolyngbya sp. E had long, straight filaments and clear trichomes. The cell content appeared to be dark green and the sheaths were thin. The ends of the filaments were also round. Leptolyngbya sp. D had very thin, long and straight, sometimes twisted filaments that clustered together. The trichomes were not very distinct due to small size. The cell content was also green in color and the apical cells seemed to be round with thin sheaths.

Although morphological appearances of Leptolyngbya spp. $A, B, D$ and $E$ suggested that all isolates belonged to genus Leptolyngbya, molecular identification is vital to ascertain their identities at species level. PCR amplification of $16 \mathrm{~S}$ rRNA gene was conducted on genomic DNA extracted from all samples and PCR product of $\sim 1500$ bp successfully amplified from all samples as depicted in Fig. 2. Comparison of partial sequences of $16 \mathrm{~S}$ rRNA with NCBI database revealed that all samples belonged to genus Leptolyngbya. Leptolyngbya spp. A, B and E were closely

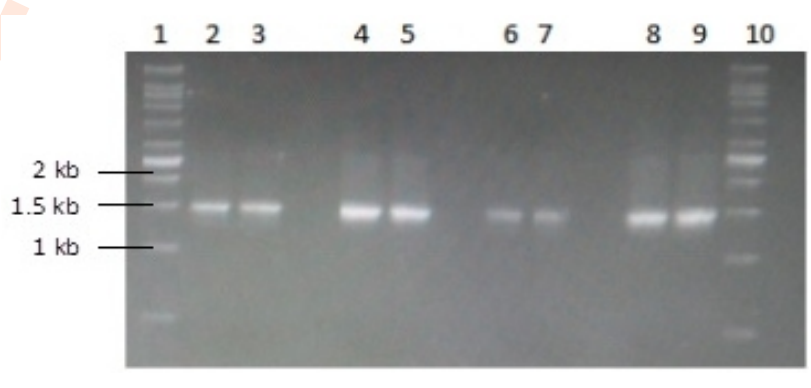

Fig. 2 : Agarose gel electrophoresis of PCR product of $16 \mathrm{~S} r R N A$ gene. Lane 1: $1 \mathrm{~kb}$ ladder; Lane 2 and 3: Sample A; Lane 4 and 5: Sample B; Lane 6 and 7: Sample D; Lane 8 and 9: Sample E; Lane 10: $1 \mathrm{~kb}$ ladder.

related to Leptolyngbya valderiana with $97 \%, 98 \%$ and $98 \%$ similarity, while Leptolyngbya $\mathrm{sp}$. D was identified as Leptolyngbya sp. (Table 1) with $98 \%$ similarity. The absence of species level for Leptolyngbya sp. D suggested the possibility of new species of Leptolyngbya and this may explain the differences in their morphology compared to Leptolyngbya spp. A, B and E.

Fig. 3 depicts the fatty acid profiles of each Leptolyngbya spp. A, B, D and E using GCMS. Based on the peaks obtained, 6 types of fatty acids were identified namely lauric acid, stearic acid, heptatriacontanoic acid, palmitoleic acid, oleic acid and linoleic 
acid. Table 2 illustrates the comparison of fatty acid percentages between Leptolyngbya spp. A, B, D and E. Though Leptolyngbya spp. A, B and E were closely related to Leptolyngbya valderiana, their fatty acid contents varied. Unsaturated fatty acids dominated the fatty acid composition of Leptolyngbya spp. A and B, but Leptolyngbya sp. E contained $83 \%$ of stearic acid and $17 \%$ of heptatriacontanoic, both belonging to saturated fatty acid (SFA). Leptolyngbya sp. A contained lauric acid (2.74\%), palmitoleic acid
(18.45\%), oleic acid (19.45\%) and linoleic acid (59.35\%), while Leptolyngbya sp. B contained $16.67 \%$ of oleic acid and $83.33 \%$ of linoleic acid. None of saturated fatty acids was detected in Leptolyngbya sp. D, instead $100 \%$ of linoleic acid which is a polyunsaturated acid (PUFA) was present in Leptolyngbya sp. D. Pushparaj et al. (2008) reported that most of Antarctic cyanobacteria were high in unsaturated fatty acid with up to $67 \%$ of total fatty acids. Additionally, in Leptolyngbya sp., the
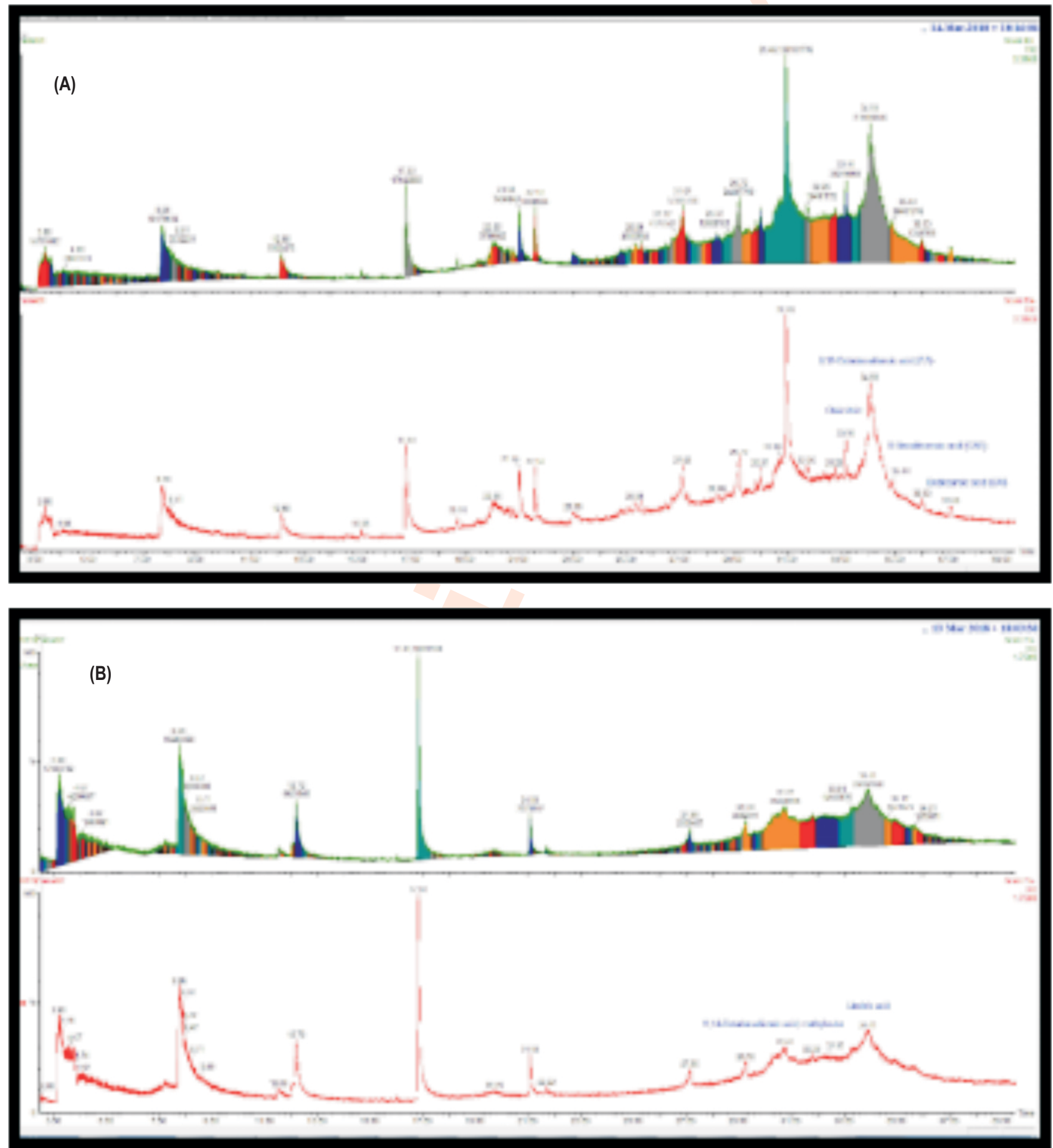

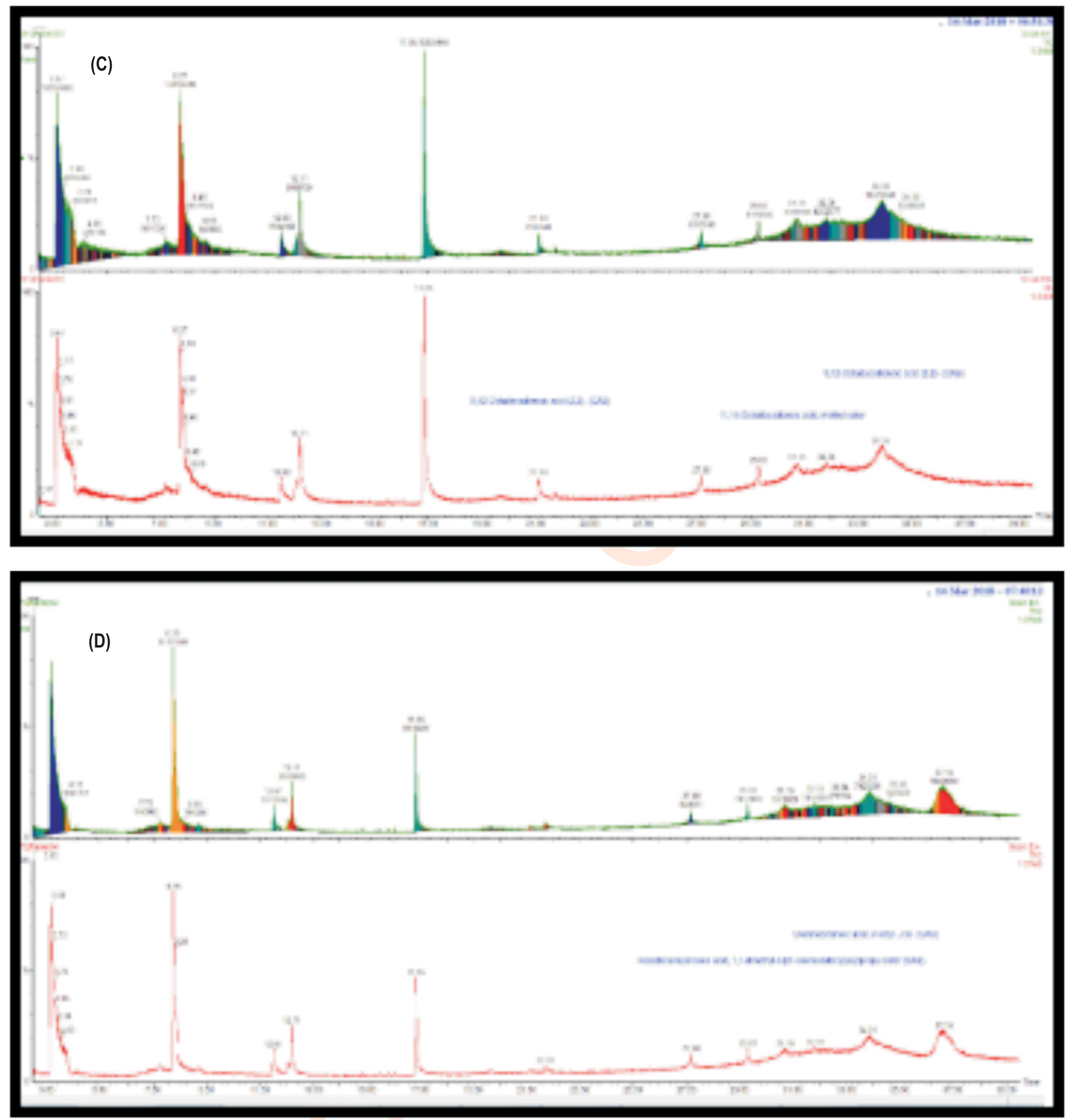

Fig. 3 : Peaks and corresponding obtained after 40 minutes of running time. (A) Peaks of fatty acid methyl ester (FAME) of Leptolyngbya sp. A; (B): Peaks of FAME Leptolyngbya sp. B; (C) Peaks of FAME Leptolyngbya sp. D and (D) Peaks of FAME Leptolyngbya sp. E.

percentage of PUFAs was higher than SFAs with the mean linoleic acid percentage being $16 \%$ of total fatty acids. Interestingly, Leptolyngbya sp. A contained $59.35 \%$ linoleic acid, Leptolyngbya sp. B contained $83.33 \%$ of linoleic acid and Leptolyngbya sp. D possessed up to $100 \%$ of linoleic acid, all of which were higher than reported by Pushparaj et al. (2008). High content of PUFAs in Leptolyngbya is a desirable trait because it can potentially be utilised as dietary supplement as well as lipid extract for medicinal purposes to treat cancer and other illness. The presence of PUFAs make these isolates valuable from nutraceutical point of view due to their health benefits, and increasing demand in the global market (Steinhoff et al., 2014). 
Linoleic acid, is valuable in the medical field as it has potential to reduce coronary heart disease and help battle cancer cells in its conjugated form (Ramsden et al., 2013). Besides, single fatty acid such as palmitoleic acid and oleic acid are of particular interest due to their health benefits. Duckett et al. (2014) reported that palmitoleic acid can promote the release of satiety hormones in rats, therefore it can open pathway for further research to implement on humans. Oleic acid helps to reduce low density lipoprotein and blood lipids and triglycerides (Lopez-Huertas, 2010). Leptolyngbya sp. E. containd only SFAs namely, stearic acid and heptatriacontanoic acid. This finding significantly differed with Martineau et al. (2013) who reported that SFAs are made up of $29.7-79 \%$ of total fatty acid in various strains of Antarctic cyanobacteria. Variations in the fatty acid composition is influenced by the difference and adaptations of each species to perform its own metabolism activities. Although SFAs seems to be underrated, SFAs do possess potential application, for example, stearic acid is commonly used as food additive and for the production of detergents, soaps and cosmetics. Heptatriacontanoic acid is a long chain saturated fatty acid with 37 carbons, an efficient compound in the neurite outgrowth activity which is highly significant in developing a novel antiAlzheimer agent (Zhang et al., 2014). Lauric acid has gained its name in the field of green technology due to significant involvement in electrospun ultrafine composite fibers that act as phase change material for storage and retrieval of solar thermal energy (Cai et al., 2012). This study highlights the fact that although cyanobacteria isolates are closely related to one species as in the case of Leptolyngbya spp. A, B and E to Leptolyngbya valderiana, their fatty acids content showed variation among them. Moreover, high content of unsaturated fatty acids was found in Leptolyngbya spp. A, B and $E$ in the range of $97 \%-100 \%$, while only saturated fatty acids were detected in Leptolyngbya sp. D. Nevertheless, fatty acids are used in various fields, and in this study Antartctic Leptolyngbya was able to synthesize fatty acids in a significant amount. Therefore, their ability to produce fatty acids should be scaled up such as growing in bioreactor or manipulating through genetic engineering, which will lead them as renewable source of biomaterials.

\section{Acknowledgment}

This work was supported by International Islamic University Malaysia.

\section{References}

Abed, R.M.M., S. Dobretsov and K. Sudesh: Applications of cyanobacteria in biotechnology. J. Appl. Microbiol., 106, 1-12 (2009).

Bela, R.B. and P. Malliga: Treatment of textile dye effluent using marine cyanobacterium Lyngbya sp. with different agrowastes and its effect on the growth of cyanobacterium. J. Environ. Biol., 36, 623$626(2015)$

Cai, Y., C. Gao., X. Xu, , Z. Fu, X. Fei, Y. Zhao, Q. Chen, X. Liu, Q. Wei, G. $\mathrm{He}$ and $\mathrm{H}$. Fong: Electrospun ultrafine composite fibers consisting of lauric acid and polyamide 6 as form-stable phase change materials for storage and retrieval of solar thermal energy. Sol. Energy Mater. Sol. Cells, 103, 53-61 (2012).

Chrismas, N.A., A.M. Anesio and P. Sánchez-Baracaldo: The future of genomics in polar and alpine cyanobacteria. FEMS Microbiol. Ecol., 94, 1-10 (2018).

Castenholz, R.W.: Oxygenic photosynthetic bacteria. In: Bergey's Manual of Systematic Bacteriology (Eds.: D.R. Boone and R.W. Castenholz). $2^{\text {nd }}$ Edn., Springer-Verlag, New York, pp. 473-600 (2001).

Dyntar, D., M. Eppenberger-eberhardt, K. Maedler, M. Pruschy, H.M. Eppenberger, G.A. Spinas and M.Y. Donath: Glucose and palmitic acid induce degeneration of myofibrils and modulate apoptosis in rat adult cardiomyocytes. Diabetes, 50, 2105-2113 (2001).

Duckett, S. K., G. Volpi-Lagreca, M. Alende and N.M. Long: Palmitoleic acid reduces intramuscular lipid and restores insulin sensitivity in obese sheep. Diabetes Metab. Syndr. Obes. , 7, 553-563 (2014).

Kien, C.L., J.Y. Bunn and F. Ugrasbul: Increasing dietary palmitic acid decreases fat oxidation and daily expenditure. Am. J. Clin. Nutr., 82, 320-326 (2018).

Kim, J.H., W. Choi, S.M. Jeon, T. Kim, A. Park, J. Kim, S.J. Heo, C. Oh, A.B. Shim and D.H. Kang: Isolation and characterization of Leptolyngbya sp. KIOST-1, a basophilic and euryhaline filamentous cyanobacterium from an open paddle-wheel raceway Arthrospira culture pond in Korea. J. Appl. Microbiol., 119, 1597 1612(2015).

Komárek, J.: Phenotype diversity of the cyanobacterial genus Leptolyngbya in the maritime Antarctic. Pol. Polar Res., 28, 211-231 (2007).

Králová, S.: Role of fatty acids in cold adaptation of Antarctic psychrophilic Flavobacterium spp. Syst. Appl. Microbiol., 40, 5-9 (2017).

Lopez-Huertas, E.: Health effects of oleic acid and long chain omega-3 fatty acids (EPA and DHA) enriched milks. A review of intervention studies. Pharmacol. Res., 61, 200-207 (2010).

Manganelli, M., S. Scardala, M. Stefanelli, F. Palazzo, E. Funari, S. Vichi, F. M. Buratti and E. Testai: Emerging health issue of cyanobacterial blooms. Ann. Ist. Super. Sanita., 48, 415-428 (2012).

Martineau, E., S.A. Wood, M.R. Miller, A.D. Jungblut, I. Hawes, J. Webster-Brown and M.A. Packer: Characterisation of Antarctic cyanobacteria and comparison with New Zealand strains. Hydrobiologia, 711, 139-154 (2013).

Oliver, R.L., D.P. Hamilton, J.D. Brookes and G.G. Ganf: Physiology, blooms and prediction of planktonic cyanobacteria. In: Ecology of Cyanobacteria II: Their diversity in Space and Time (Ed.: B.A. Whitton). Dordrecht: Springer Netherlands (2012).

Pushparaj, B., A. Buccioni, R. Paperi, R. Piccardi, A. Ena, P. Carlozzi and C. Sili: Fattyacid composition of Antarctic cyanobacteria. Phycologia, 47, 430-434 (2008).

Ramsden, C.E., D. Zamora, B. Leelarthaepin, S.F. Majchrzak-Hong, K.R. Faurot, C.M. Suchindran, A. Ringel, J.M. Davis and J.R. Hibbeln: Use of dietary linoleic acid for secondary prevention of coronary heart disease and death: Evaluation of recovered data from the Sydney Diet Heart Study and updated meta-analysis. BMJ (Online), 346, 1-18 (2013).

Rippka, R., J. Deruelles, B. Waterbury, M. Herdman and R.Y. Stanier: Generic assignments, strains histories and properties of pure cultures of cyanobacteria. J. Gen. Microbiol., 111, 1-61 (1979).

Sasser, M.: Identification of bacteria by gas chromatography of cellular fatty acids. MIDI Technical Note 101. Newwark, DE: MIDI Inc., 1-6 (2001). 
Schopf, J.W.: The fossil record of cyanobacteria. In: Ecology of Cyanobacteria II: Their Diversity in Space and Time (Ed.: B.A. Whitton). Dordrecht: Springer Netherlands (2012).

Sharma, R., O.P. Chahar, M. Bhatnagar and A. Bhatnagar: Impact of osmotic stress and temperature on pigments and proteins of Anabaena strains. J. Environ. Biol., 34, 941-943 (2013).

Singh, S.P. and B.L. Montgomery: Determining cell shape: Adaptive regulation of cyanobacterial cellular differentiation and morphology. Trends Microbiol., 19, 278-285 (2011).

Steinhoff, F.S., M. Karlberg, M. Graeve and A. Wulff: Cyanobacteria in Scandinavian coastal waters - a potential source for biofuels and fatty acids? Algal. Res., 5, 42-51 (2014).

Taton, A., E. Lis, D.M. Adin, G. Dong, S. Cookson, S.A. Kay, S.S. Golden and J.W. Golden: Gene transfer in Leptolyngbya sp. strain BL0902, a cyanobacterium suitable for the production of biomass and bioproducts. PLOS ONE, 7, e30901 (2012).

Terés, S., G.B. Coblijn, M. Benet, R. Alvarez, R. Bressani, J.E. Halver and P.V. Escribá: Oleic acid content is responsible for the reduction in blood pressure induced by olive oil. Proc. Natl. Acad. Sci. USA, 105, 13811-13816 (2008).
Üveges, V., K. Tapolczai, L. Krienitz and J. Padisák: Photosynthetic characteristics and physiological plasticity of an Aphanizomenon flos-aquae (Cyanobacteria, Nostocaceae) winter bloom in a deep oligo-mesotrophic lake (Lake Stechlin, Germany). Hydrobiologia, 698, 263-272 (2012)

Wilmotte, A. and M. Herdman: Phylogenetic relationships among the cyanobacteria based on 16S rRNA sequences. In: Bergey's Manual of Systematic Bacteriology (Eds.: G.M. Garrity, D.R. Boone and R.W. Castenholz). Springer-Verlag, New York, NY, pp. 487-599 (2001).

Vincent, W.F.: Cold tolerance in cyanobacteria and life in the cryosphere. In: Algae and Cyanobacteria in Extreme (Ed.: J. Seckbach). Environments Springer (2007).

Zakhia, F., A. Jungblut, A. Taton, W.F. Vincent and A. Wilmotte: Cyanobacteria in cold ecosystems. In: Psychrophiles: from Biodiversity to Biotechnology (Eds.: R. Margesin, F. Schinner, J.C. Marx and C. Gerday), pp. 121-135 (2008).

Zhang, H.Y., Y.I. Yamakawa, Y. Matsuya, N. Toyooka, C. Tohda, S. Awale, F. Li, S. Kadota and Y. Tezuka: Synthesis of long-chain fatty acid derivatives as a novel anti-Alzheimer's agent. Bioorg. Med. Chem. Lett., 24, 604-608 (2014). 